Research Paper

\title{
BolA family member 2 enhances cell proliferation and predicts a poor prognosis in hepatocellular carcinoma with tumor hemorrhage
}

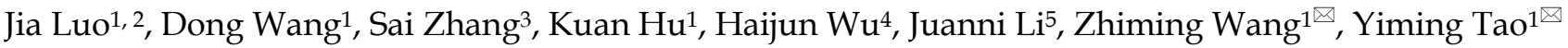 \\ 1. Department of General Surgery, Xiangya Hospital, Central South University, Changsha 410008, China. \\ 2. Department of Surgery, Hunan Provincial Tumor Hospital, Changsha 410006, Hunan, China. \\ 3. Institute of Medical Sciences, Xiangya Hospital, Central South University, Changsha 410008, China. \\ 4. Department of Oncology, Xiangya Hospital, Central South University, Changsha 410008, China. \\ 5. Department of Pathology, Xiangya Hospital, Central South University, Changsha 410008, China. \\ $\square$ Corresponding authors: Yi-Ming Tao, M.D., Zhiming Wang, M.D., Department of General Surgery, Xiangya Hospital, Central South University. Address: 87 \\ Xiang Ya Road, Changsha, Hunan, China 410008. Phone number: +86-731-8432-7191; Fax: +86-731-8975-3510; E-mail: yimingtao@csu.edu.cn, \\ zhimingwang@csu.edu.cn.
}

(c) The author(s). This is an open access article distributed under the terms of the Creative Commons Attribution License (https://creativecommons.org/licenses/by/4.0/). See http://ivyspring.com/terms for full terms and conditions.

Received: 2018.11.27; Accepted: 2019.05.26; Published: 2019.07.10

\begin{abstract}
Objective: BolA family member 2 (BOLA2) is a novel gene highly associated with human hepatocellular carcinoma (HCC) progression. Tumor hemorrhage (TH) acts as a poor marker for HCC patients and is a community affair in the tumor microenvironment. In the present study, we examined a possible association between BOLA2 levels and HCC patients with $\mathrm{TH}$.

Methods: The mRNA and protein levels of BOLA2 were determined in two independent cohorts of HCC specimens by quantitative real-time polymerase chain reaction (qRT-PCR) and immunohistochemistry (IHC) analysis, respectively. Survival curves and Cox regression models were used to evaluate the prognosis of HCC patients. The CRISPR/Cas9 system was used to knock out BOLA2 in HCC cells, and the functional role of BOLA2 in HCC cell proliferation in vitro and growth in vivo was examined.

Results: BOLA2 mRNA expression is significantly higher in HCC tumour tissue than in nontumour tissue. Immunohistochemistry analysis of HCC tissues showed that BOLA2 protein was significantly correlated with $\mathrm{TH}$, a more metastatic phenotype and worse HCC survival. The potential clinical relevance of BOLA2 expression and $\mathrm{TH}$ was validated by a Cox regression model. Furthermore, loss-of-function studies determined that BOLA2 plays critical roles in promoting iron overload, tumor growth and $\mathrm{TH}$. Bioinformatics analysis from Gene Expression Profiling Interactive Analysis (GEPIA) revealed that BOLA2 is closely associated with the activation of p62-Keapl signalling and ATG4B expression. These results were confirmed by immunohistochemistry analysis in HCC tissues.

Conclusions: Our results suggest that BOLA2 plays an important role in cancer biology and is an independent predictor of prognosis in HCC.
\end{abstract}

Key words: Hepatocellular carcinoma; BolA family member 2; Iron metabolism; Tumor hemorrhage; Tumor microenvironment

\section{Introduction}

Hepatocellular carcinoma (HCC) is one of the most malignant tumors and has an extremely poor prognosis [1]. The tumor microenvironment plays a critical role in promoting HCC progression and metastasis [2]. As an underlying key indicator of a fast-growing tumor, tumor hemorrhage $(\mathrm{TH})$ is associated with progression and metastasis [3]. TH has been demonstrated to be a poor marker for HCC patients [4]. Therefore, determining the underlying mechanistic basis of these pathogenetic changes in HCC could greatly benefit the efficacy of the clinical treatment of HCC. 
BolA family member 2 (BOLA2) is a nonclassical secreted member of the BolA protein family that also contains BOLA1, BOLA2 and BOLA3 [5]. Previous studies have revealed that BOLA2 functions as a key regulatory for intracellular iron homeostasis in the microenvironment [6, 7]. Increasing evidence has revealed that iron homeostasis dysregulation is linked to cancer initiation and development [8, 9]. BOLA2 was also reported to potently promote c-Myc's oncogenic activity in liver cancer [10]. Although its expression was reported to be elevated during tumorigenesis, BOLA2 has not been extensively studied in cancer, including HCC.

For the first time, we investigated the expression of BOLA2 expression in both HCC recurrence and metastasis and evaluated the significance of BOLA2 in the prediction of HCC prognosis, especially $\mathrm{TH}$. We analysed the expression and functions of BOLA2 in $\mathrm{HCC}$ cell growth and $\mathrm{TH}$. Our findings suggest that BOLA2 can be a potential therapeutic target for the treatment of HCC metastasis.

\section{Materials and Methods}

\section{Patient populations and follow-up}

For the use of clinical HCC tissues for research purposes, informed consent was obtained from each HCC patient before hepatic resection. All patients and the study protocol were approved by the Ethics Committee of Central South University (Xiangya Hospital, China). Two independent cohorts of HCC specimens were examined in this study. In the training cohort $(n=96)$, fresh matched specimens of HCC and adjacent non-tumor tissue (NT) were randomly collected from HCC patients undergoing hepatic resection between August 2011 and October 2011 in the Department of Hepatobiliary Surgery, Xiangya Hospital, China. In the validation cohort $(n=175)$, paraffin-embedded specimens were randomly collected from HCC patients undergoing curative resection in Xiangya Hospital from March 2012 to November 2012. HCC specimens accompanied with $\mathrm{TH}$ were reviewed by two independent pathologists in our hospital. The following procedures from our previous study were adopted [11]. Follow-up of HCC patients was terminated on 31 January 2017. All research protocols strictly complied with REMARK guidelines for reporting prognostic biomarkers in cancer [12].

\section{HCC cell lines}

HepG2, Hep3B, SNU449 and PLC/PRF5 cells were obtained from the American Type Culture Collection (ATCC, Rockville, MD). L02, SMMC7721, Bel7402 and Huh7 cells were purchased from the Cell Bank of Typical Culture Preservation Committee of
Chinese Academy of Science (Shanghai, China). L02 is a normal liver cell line that is usually used as a control cell in cancer research. MHCC97L cell lines were provided by the Liver Cancer Institute of Zhongshan Hospital of Fudan University (Shanghai, China). The characteristics and proteome analysis of MHCC97L have been previously described [13]. All cell lines were routinely authenticated by STR genotyping and mycoplasma detection. Cells were stored in liquid nitrogen and cultured in $5 \% \mathrm{CO}_{2}$ at $37^{\circ} \mathrm{C}$ with high-glucose Dulbecco's modified Eagle media (GIBCO, Grand Island, NY) supplemented with penicillin $(100 \mathrm{IU} / \mathrm{mL})$, streptomycin $(100 \mathrm{mg} / \mathrm{mL})$ and $10 \%$ FBS (GIBCO).

\section{Quantitative RT-PCR in clinical HCC specimens}

The procedures of SYBR green fluorescent-based quantitative reverse transcriptase polymerase chain reaction (qRT-PCR) were performed as previously described [11]. Actin was used as a control for BOLA2 gene detection. The oligonucleotide sequences for BOLA2 and $\beta$-actin primers were as follows: BOLA2, 5'-CTGTAGCTTCCGAGTCCTG, 3'-TTCAAAGGCA TGGATGTGC; and $\beta$-actin, $5^{\prime}$-GGACTTCGAGCAA GAGATGG, 3'-AGCACTGTGTTGGCGTACAG.

\section{Immunohistochemistry (IHC) analysis}

IHC analysis and scoring were performed as previously described [14]. A BOLA2 polyclonal antibody (GeneTex, MA, USA, Cat. \# GTX51984) diluted at 1:1000 was used as the primary antibody. A peroxidase-labelled polymer was conjugated to goat anti-rabbit IgG (DAKO Corporation, Carpinteria, CA, Cat. \# K5007) for 30 minutes at room temperature, and color was developed using 3, 3'-diaminobenzidine (DAB) solution. BOLA2 expression was assessed when cytoplasmic or membranous staining was observed.

\section{Western blot analysis}

Western blot analysis were performed as previously described [15]. The antibody dilutions were 1:1,000 for the BOLA2 polyclonal antibody (Cat. \# ab169481, Abcam), 1:1,000 for the p62 polyclonal antibody (ABGNT, Cat. \# AP2183B), 1:1,000 for the Keap1 polyclonal antibody (ABGNT, Cat. \# ALS15665), and $1: 5,000$ for the $\beta$-actin mouse monoclonal antibody (Sigma-Aldrich, Cat. \# A1978). All Western blot images were analysed with ImageJ software (NIH) to determine signal intensity.

\section{Establishment of BOLA2-knockout HCC cell lines}

The characteristics of HCC Hep3B cells with high intracellular iron content have been described in 
the literature [16]. BOLA2-deficient Hep3B cells were established using the CRISPR/Cas9 system. The gRNA was selected with the assistance of the CRISPR design tool according to a standard protocol [17]. The sgRNA sequences of BOLA2 were 5'-CATGGCAAGC GCGAAAAGCC-3'; and bottom strand: 5'-TCACCA CATGCTCCGCCTCC-3'. For control cells, no guide RNA was inserted. Each experimental replicate was performed using the HCC cell line Hep3B.

\section{Cell proliferation assay}

Eight hundred Hep3B cells per well were grown in 96-well plates, and a cell proliferation assay was performed using a Cell Counting Kit-8 (Med Chem Express, USA, Cat. \# HY-K0301) according to the manufacturer's protocol. Each experiment was repeated three times.

\section{Colony-forming assay}

Hep3B cells were seeded into six-well plates (1000 cells/well). After incubation for 14 days, the colonies that formed were washed and then stained with $0.2 \%$ crystal violet (Fisher Scientific, Asheville, NC, Cat. \# R40053). The colonies were quantified from three independent experiments per treatment group.

\section{Tumor xenograft model}

All animal work was conducted in accordance with protocols approved by the Animal Care and Use Committee at Central South University, China. A subcutaneous HCC mouse model was established according to an existing protocol [18]. BOLA2-knockout Hep3B cells $\left(2 \times 10^{6}\right.$ cells/mouse) were injected subcutaneously into the right axilla (200 $\mu l)$. All nude mice were sacrificed six weeks after tumor implantation. Prussian blue staining (Sigma-Aldrich, Cat. \# 03899) was performed on sections of each transplanted tumor lesion. In addition, IHC staining against BOLA2, p62 and Ki-67 was performed on paraffin sections.

\section{Bioinformatics prediction}

We used the Oncomine database (www.oncomine.com) to predict the levels of BOLA2 mRNA in HCC and normal tissues. Then, Gene Expression Profiling Interactive Analysis (GEPIA) (http://gepia.cancer-pku.cn/) was employed to forecast a potential correlation between BOLA2 mRNA expression levels and the overall survival of HCC patients [19]. Images of BOLA2 protein expression in HCC specimens and normal liver tissues were obtained from the Human Protein Atlas (www.proteinatlas.org) online database [20]. Tumor Immune Estimation Resource (TIMER) (https://cistrome.shinyapps.io/timer/) was used to study the correlation between the BOLA2 gene and a pair of user-defined genes in liver hepatocellular carcinoma (LIHC) [21]. A protein-protein interaction network of BOLA2 highly correlated genes was generated by the STRING database (http:// string-db.org).

\section{Statistical analysis}

Statistical analyses were performed using SPSS version 20.0 (SPSS, Chicago, IL, USA) and GraphPad Prism software (GraphPad Software, San Diego, CA). Quantitative values are presented as the mean \pm SD or median (range). Paired $t$ tests and Student's tests were used for paired and unpaired continuous data, respectively. The $\chi^{2}$ test was applied for categorical data. The cumulative overall survival (OS) and recurrence-free survival (RFS) were evaluated using the Kaplan-Meier method and the log-rank test. A Cox proportional hazards regression model was used to determine whether BOLA2 expression is an independent prognostic indicator. Statistically significant changes are indicated with asterisks. ${ }^{*}=(P$ $<0.05){ }^{* *}=(P<0.01) ;{ }^{* * *}=(P<0.001)$.

\section{Results}

\section{Overexpression of BOLA2 correlated with poor survival in $\mathrm{HCC}$}

We performed a pan-cancer analysis of the expression of BOLA2 genes in normal and cancerous tissues by using the Oncomine database and found that BOLA2 was increased in most types of solid tumors, including breast, colorectal, pancreatic, and liver (Figure 1). Similar results were found through the online GEPIA database (Figure 2A). BOLA2 mRNA was significantly increased in HCC compared with normal liver tissues $(P<0.05$, Figure $2 B)$. High levels of BOLA2 mRNA also strongly correlated with a higher HCC stage, worse survival $(P=0.0095)$ and disease-free survival $(P=0.047)$ (Figure 2C). In addition, the human protein atlas verified a similar expression trend of BOLA2 protein within HCC samples (Figure 2D).

\section{Association between BOLA2 and TH}

We examined the relative transcription levels of BOLA2 by qRT-PCR in tumor tissues and corresponding nontumour tissue (NT) in a cohort of 96 HCC patients. The mRNA expression of BOLA2 in the HCC tumor tissues of the training cohort significantly correlated with the clinicopathological features of tumor invasion and aggression, such as venous invasion, satellite nodules, tumor hemorrhage (TH), tumor differentiation and HCC stage (Table 1). Intriguingly, when 96 HCC tumors were classified into subgroups by $\mathrm{TH}$ or not (Figure 3A), HCC 
tumors with $\mathrm{TH}$ showed even higher expression of BOLA2 $(1.748 \pm 0.118$ versus $2.317 \pm 0.135, P<0.01$; Figure 3B). TH indicated a worse tumor immunological microenvironment [4, 22]. As shown in Figure 3C, by using TIMER, a positive correlation was observed between BOLA2 mRNA expression and defined reactive oxygen species (ROS) modulator genes in HCC, such as p62, autophagy-related 4B (ATG4B) and Kelch-like ECH-associated protein 1 (Keap1), whereas BOLA2 mRNA expression was inversely correlated with nuclear factor erythroid 2-related factor 2 (NRF2). These results suggest that BOLA2 expression correlates with oxidative stress and $\mathrm{TH}$.

Table 1. Correlation between BOLA2 mRNA expression and clinicopathological characteristics in $96 \mathrm{HCC}$ patients

\begin{tabular}{lllll}
\hline Clinical and pathological variable & \multicolumn{3}{l}{ BOLA2 mRNA } & \\
\cline { 3 - 5 } & & $\begin{array}{l}\text { Low expression } \\
(\mathrm{n}=39)\end{array}$ & $\begin{array}{l}\text { Overexpression } \\
(\mathrm{n}=57)\end{array}$ & P value† \\
\hline Age, years & $\leq 60$ & 22 & 33 & 0.885 \\
& $>60$ & 17 & 24 & 0.075 \\
Sex & Male & 26 & 47 & \\
& Female & 13 & 10 & 0.069 \\
Child-Pugh score & A & 25 & 46 & \\
\hline
\end{tabular}

\begin{tabular}{|c|c|c|c|c|}
\hline \multirow{2}{*}{\multicolumn{2}{|c|}{ Clinical and pathological variable }} & \multirow{2}{*}{\multicolumn{3}{|c|}{ BOLA2 mRNA }} \\
\hline & & & & \\
\hline & $\mathrm{B}$ & $\begin{array}{l}\text { Low expression } \\
(\mathrm{n}=39) \\
14\end{array}$ & $\begin{array}{l}\begin{array}{l}\text { Overexpression } \\
(\mathrm{n}=57)\end{array} \\
11\end{array}$ & $P$ valuef \\
\hline \multirow{2}{*}{ Albumin, g/L } & $\leq 35$ & 7 & 4 & \multirow[t]{2}{*}{0.099} \\
\hline & $>35$ & 32 & 53 & \\
\hline \multirow[t]{2}{*}{$\mathrm{AFP},(\mathrm{ng} / \mathrm{mL})$} & $\leq 20$ & 18 & 19 & \multirow[t]{2}{*}{0.205} \\
\hline & $>20$ & 21 & 38 & \\
\hline \multirow[t]{2}{*}{ Liver cirrhosis } & Absent & 7 & 5 & \multirow[t]{2}{*}{0.182} \\
\hline & Present & 32 & 52 & \\
\hline \multirow[t]{2}{*}{ Tumor size, $(\mathrm{cm})$} & $\leq 5$ & 17 & 16 & \multirow[t]{2}{*}{0.116} \\
\hline & $>5$ & 22 & 41 & \\
\hline \multirow[t]{2}{*}{ Tumor number } & Single & 25 & 26 & \multirow[t]{2}{*}{0.075} \\
\hline & Multiple & 14 & 31 & \\
\hline \multirow[t]{2}{*}{ Tumor encapsulation } & Complete & 18 & 16 & \multirow[t]{2}{*}{0.069} \\
\hline & None & 21 & 41 & \\
\hline \multirow[t]{2}{*}{ Satellite nodules } & Absent & 23 & 18 & \multirow[t]{2}{*}{0.008} \\
\hline & Present & 16 & 39 & \\
\hline \multirow[t]{2}{*}{ Venous invasion } & Absent & 25 & 10 & \multirow[t]{2}{*}{$<0.0001$} \\
\hline & Present & 14 & 47 & \\
\hline \multirow[t]{2}{*}{ Tumor differentiation } & I-II & 8 & 24 & \multirow[t]{2}{*}{0.028} \\
\hline & III-IV & 31 & 33 & \\
\hline \multirow[t]{2}{*}{ Tumor hemorrhage } & Absent & 21 & 10 & \multirow[t]{2}{*}{0.0002} \\
\hline & Present & 18 & 47 & \\
\hline \multirow[t]{2}{*}{ BCLC stage } & A & 23 & 13 & \multirow[t]{2}{*}{0.0003} \\
\hline & $\mathrm{B}-\mathrm{C}$ & 16 & 44 & \\
\hline \multirow[t]{2}{*}{ TNM stage } & I & 18 & 12 & \multirow[t]{2}{*}{0.009} \\
\hline & II-III & 21 & 45 & \\
\hline
\end{tabular}

† Fisher's exact test or the chi-square test.

A significant difference is shown in bold.
Disease Summary for BOLA2

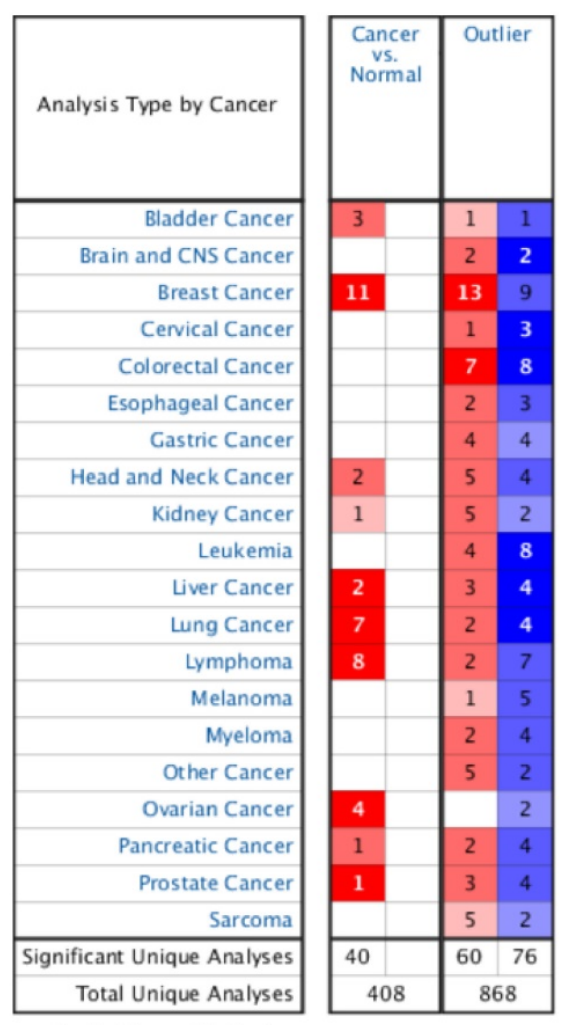

$1 \stackrel{5}{10} \square^{10} \square^{5} \square^{1}$
Fold Change:2.676 P-value: $3.72 \mathrm{E}-83$
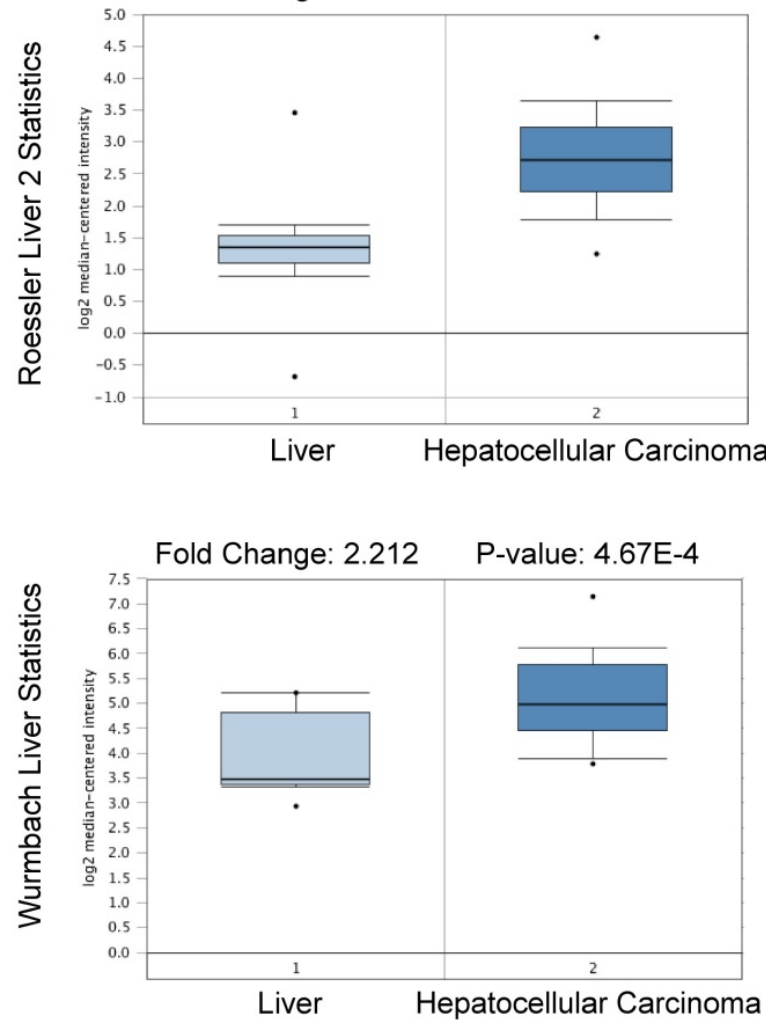

Fig. 1. High expression levels of BOLA2 mRNA in HCC predicted by the Oncomine database. BOLA2 mRNA levels in Roessler Liver2 (GEO: GSE 14520/GPL3921) and Wurmbach Liver (GEO: GSE 6764) grouped by HCC and normal liver in the Oncomine database. 
A

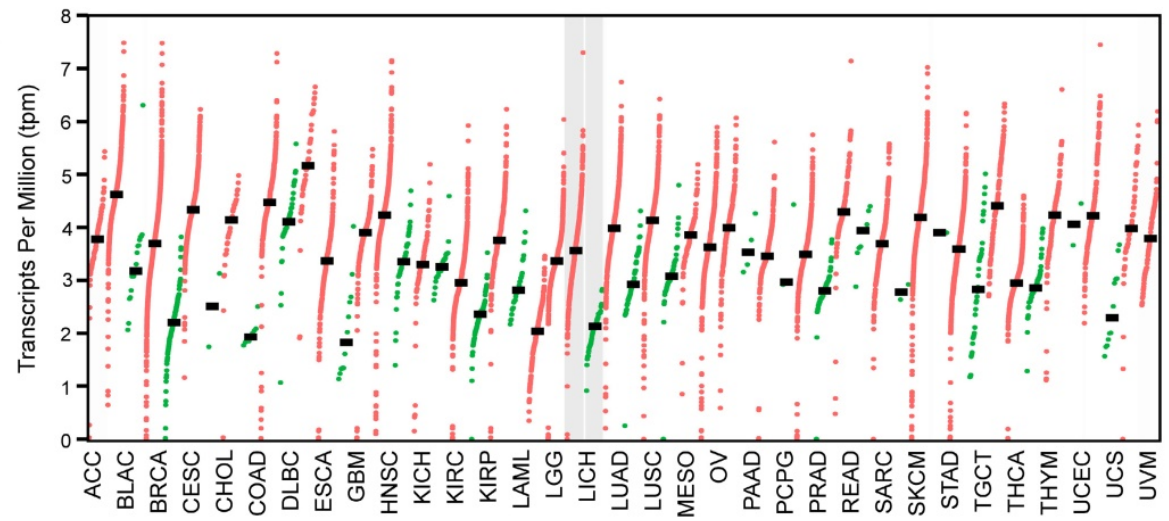

B

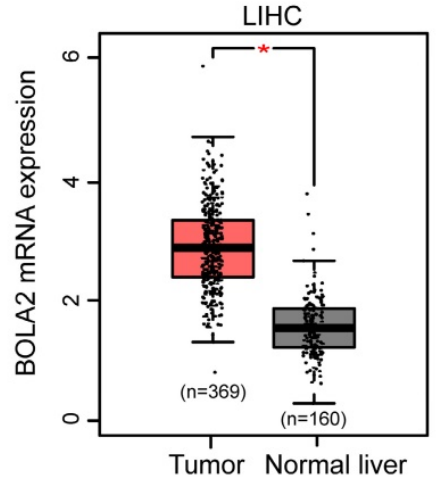

C

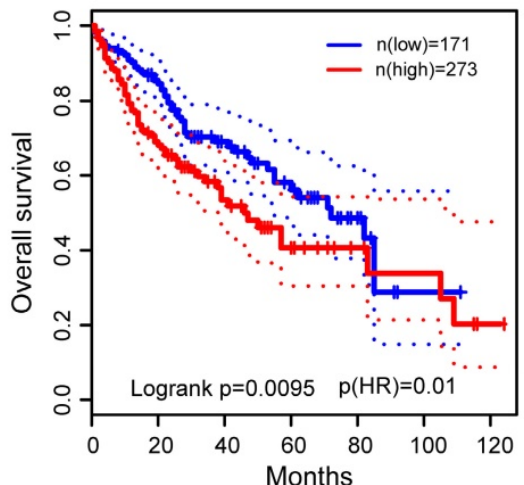

D
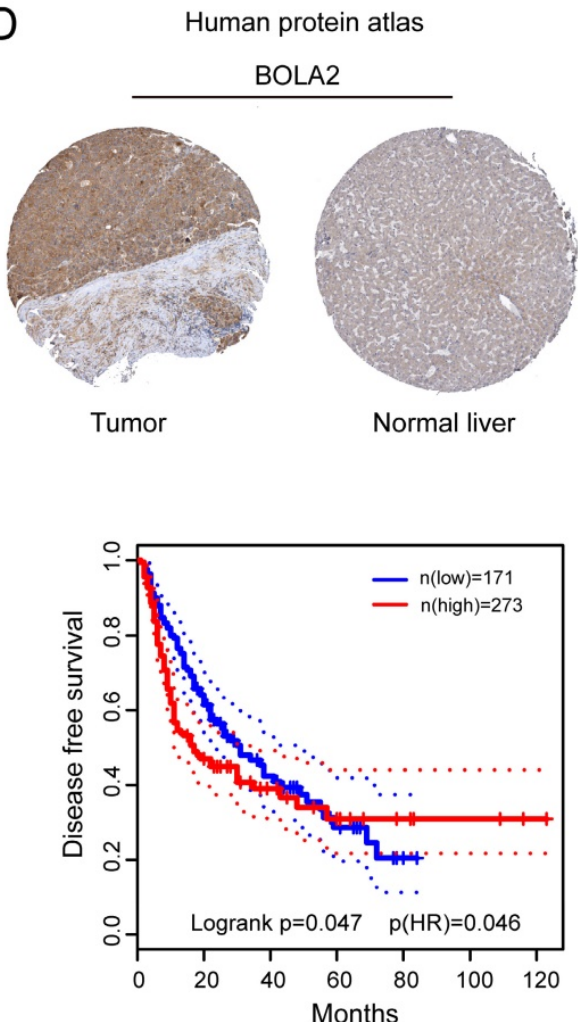

Fig. 2. BOLA2 expression level is significantly increased in $\mathrm{HCC}$ and is associated with poor clinical outcomes. (A) Differential expression of BOLA2 between tumor and adjacent normal tissues from various types of cancer. (B) BOLA2 gene expression was significantly increased in HCC ( $=369$ ) compared with corresponding normal liver tissues ( $\mathrm{n}=160$ ). Data were extracted from the GEPIA web server. (C) Kaplan-Meier curves stratified by BOLA2 mRNA expression. Overall survival and disease-free survival data were generated from the GEPIA web server. (D) BOLA2 protein expression in normal liver tissues and HCC specimens. Images were obtained from the Human Protein Atlas online database.

\section{BOLA2 expression predicts clinical outcome in HCC}

To confirm the above results, in a training cohort of HCC samples, we validated the expression of BOLA2, p62, Keap1, NRF2, and ATG4B and the proliferation marker (Ki-67) using immunohistochemistry (Figure 4A). HCC patients with $\mathrm{TH}$ and lower BOLA2 expression had higher levels of NRF2, whereas patients with higher BOLA2 expression had increased ATG4B, p62 and Keap1 levels (Figure 4B). Furthermore, HCC patients with TH showed even higher Ki-67 expression (Figure 4C). Moreover, the expression levels of BOLA2 protein were confirmed in another validation cohort containing 175 HCC patients (Table 2). Cox's multivariate analysis indicated that BOLA2 expression was an independent positive prognostic factor in the training cohort $(\mathrm{HR}=2.108,95 \%$ CI 1.541 to 6.067; Table 3). The BOLA2 ${ }^{\text {high }}$ expression group exhibited worse overall survival (OS) and shorter recurrence-free survival (RFS) than the BOLA2low expression group (Figure 4D and 4E). The 1-, 3-, and 5 -year OS rates in the high expression group were significantly lower than those in the low expression group $(60.2 \%$ versus $79.8 \%, 28.4 \%$ versus $48.5 \%$, and $18.2 \%$ versus $45.7 \%$, respectively). The $1-, 3-$, and 
5-year RFS rates were markedly lower in the high expression group than in the low expression group (52.2\% versus $75.6 \%, 18.4 \%$ versus $39.7 \%$, and $16.6 \%$ versus $43.4 \%$, respectively). Taken together, these results suggest that the value of BOLA2 may be a clinical predictor of HCC prognosis.

Table 2. Correlation between BOLA2 protein and clinicopathological characteristics in $175 \mathrm{HCC}$ patients

\begin{tabular}{|c|c|c|c|c|}
\hline \multirow{2}{*}{\multicolumn{2}{|c|}{$\begin{array}{l}\text { Clinical and pathological } \\
\text { variable }\end{array}$}} & \multicolumn{3}{|l|}{ BOLA2 protein } \\
\hline & & \multirow{2}{*}{$\begin{array}{l}\begin{array}{l}\text { Low expression } \\
(\mathrm{n}=57)\end{array} \\
36\end{array}$} & \multirow{2}{*}{$\begin{array}{l}\text { High expression } \\
(\mathrm{n}=118)\end{array}$} & \multirow{2}{*}{$\begin{array}{l}P \text { value } \\
0.264\end{array}$} \\
\hline Age, years & $\leq 60$ & & & \\
\hline & $>60$ & 21 & 54 & \\
\hline \multirow[t]{2}{*}{ Sex } & Male & 47 & 86 & 0.165 \\
\hline & Female & 10 & 32 & \\
\hline \multirow[t]{2}{*}{ Child-Pugh score } & A & 38 & 93 & 0.083 \\
\hline & $\mathrm{B}$ & 19 & 25 & \\
\hline \multirow[t]{2}{*}{ Albumin, g/L } & $\leq 35$ & 9 & 11 & 0.208 \\
\hline & $>35$ & 48 & 107 & \\
\hline \multirow{2}{*}{$\mathrm{AFP},(\mathrm{ng} / \mathrm{mL})$} & $\leq 200$ & 26 & 41 & 0.258 \\
\hline & $>200$ & 31 & 71 & \\
\hline \multirow[t]{2}{*}{ Liver cirrhosis } & Absent & 10 & 12 & 0.168 \\
\hline & Present & 47 & 106 & \\
\hline \multirow[t]{2}{*}{ Tumor size, $(\mathrm{cm})$} & $\leq 5$ & 24 & 36 & 0.130 \\
\hline & $>5$ & 33 & 82 & \\
\hline \multirow[t]{2}{*}{ Tumor number } & Single & 36 & 57 & 0.065 \\
\hline & Multiple & 21 & 61 & \\
\hline \multirow{2}{*}{$\begin{array}{l}\text { Tumor } \\
\text { encapsulation }\end{array}$} & Complete & 23 & 39 & 0.344 \\
\hline & None & 34 & 79 & \\
\hline \multirow[t]{2}{*}{ Satellite nodules } & Absent & 42 & 33 & $<0.0001$ \\
\hline & Present & 15 & 85 & \\
\hline \multirow[t]{2}{*}{ Venous invasion } & Absent & 37 & 27 & $<0.0001$ \\
\hline & Present & 20 & 91 & \\
\hline \multirow{2}{*}{$\begin{array}{l}\text { Tumor } \\
\text { differentiation }\end{array}$} & I-II & 9 & 49 & 0.001 \\
\hline & III-IV & 48 & 69 & \\
\hline Tumor hemorrhage & Absent & 27 & 30 & 0.004 \\
\hline
\end{tabular}

A
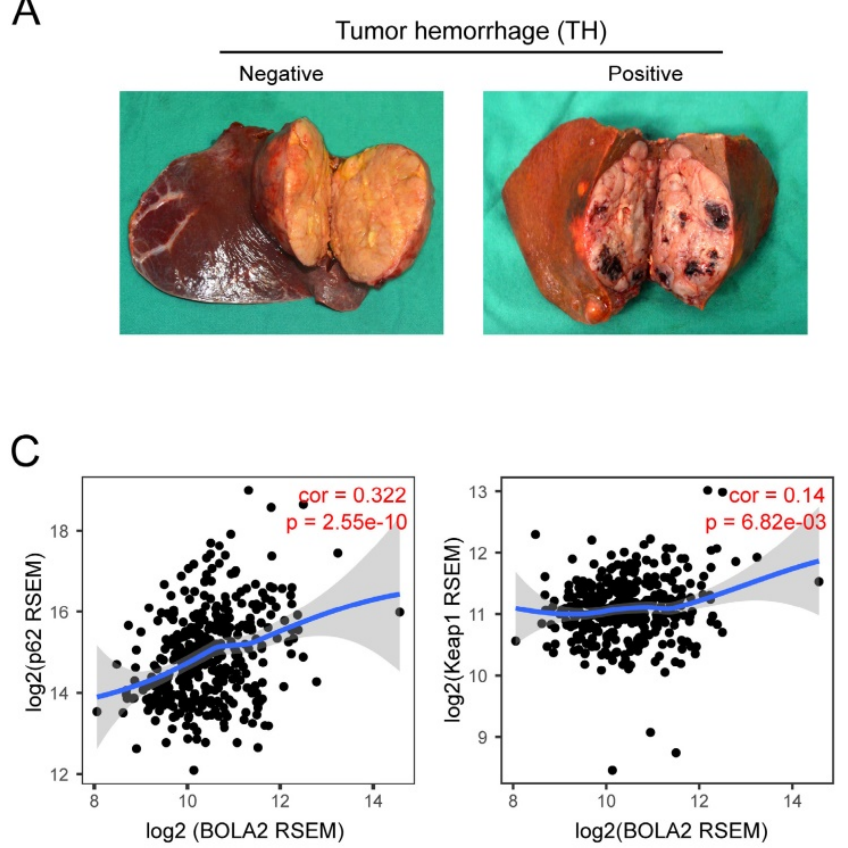

\begin{tabular}{lllll}
\hline $\begin{array}{l}\text { Clinical and pathological } \\
\text { variable }\end{array}$ & \begin{tabular}{l} 
BOLA2 protein \\
\cline { 3 - 5 }
\end{tabular} & $\begin{array}{l}\text { Low expression } \\
(\mathrm{n}=57)\end{array}$ & $\begin{array}{l}\text { High expression } \\
(\mathrm{n}=118)\end{array}$ & $P$ value \\
\hline \multirow{2}{*}{ BCLC stage } & Present & 30 & 88 & \\
& A & 31 & 35 & $\mathbf{0 . 0 0 2}$ \\
TNM stage & B-C & 26 & 83 & \\
& I & 26 & 29 & 0.005 \\
& II-III & 31 & 89 & \\
\hline
\end{tabular}

A significant difference is shown in bold.

\section{BOLA2 knockout suppresses HCC cell proliferation, tumor growth and $\mathrm{TH}$}

The protein levels of BOLA2 among eight established HCC cell lines were compared with the immortalized human hepatocyte cell line L02. BOLA2 expression was higher in HCC cells than in L02 cells (Figure 5). We knocked out BOLA2 in Hep3B cell lines using CRISPR/Cas9 technology and evaluated the effects of BOLA2 in these cells. BOLA2 modulation exhibited significant effect on the protein expression of p62 and Keap1 in BOLA2-deficient Hep3B cells (Figure 6A). Cell proliferation assays revealed that BOLA2 knockout potently slowed cell proliferation compared with the WT cell group (Figure 6B). Compared with WT cells at day 4, the suppressive rates were $37.5 \%$ (KO-1) and $33.3 \%$ (KO-3) in the three BOLA2-deficient colonies derived from Hep3B cells. Cell colony assays further confirmed the similar suppressive effects of BOLA2 knockout (Figure 6C), with inhibitory rates of $45.3 \%$ and $33.6 \%$ in Hep3B $\mathrm{KO}-1$ and $\mathrm{KO}-3$ cells, respectively. These findings indicate the oncogenic role of BOLA2 in HCC tumor progression.
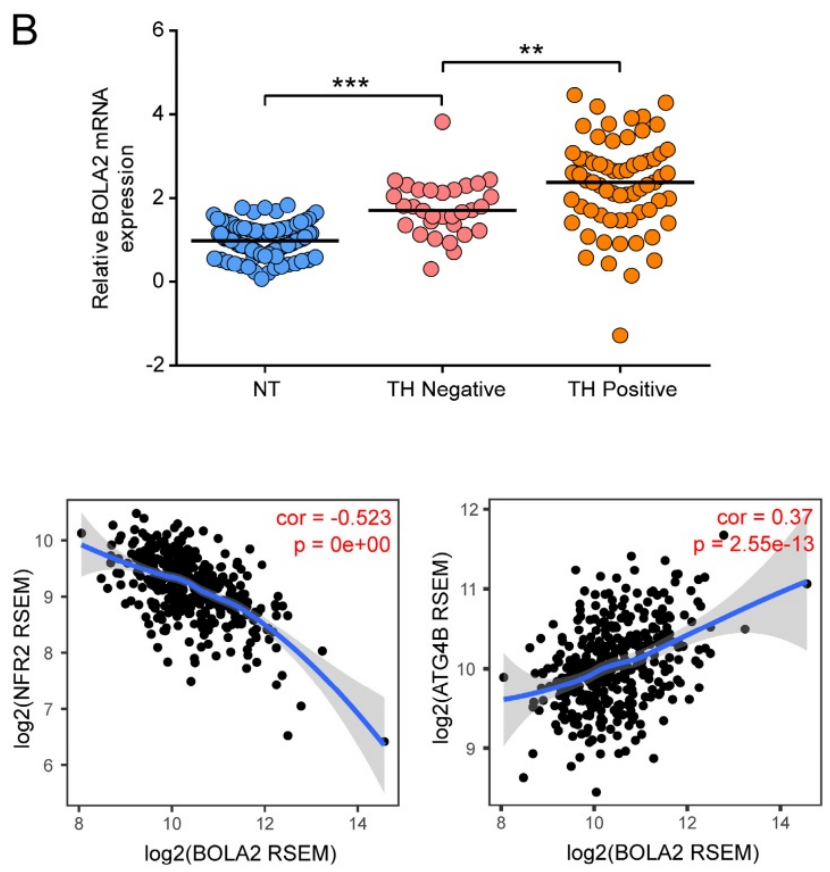

Fig. 3. Increased expression of BOLA2 mRNA is related to a high risk of TH. (A) Representative gross specimens of HCC with/without TH. (B) BOLA2 expression in a NT, a TH-negative tumor, and a TH-positive tumor. ** $P<0.01$. *** $P<0.001$. Abbreviations: NT, nontumor tissues. (C) Spearman's correlation analysis of tumor oxidative stress markers, including p62, Keap1, Nrf2, and ATG4B, with BOLA2 expression in the HCC profiles of the TCGA dataset. 
Next, we attempted to determine whether BOLA2 knockout had the same suppressive effects on HCC tumor growth in vivo. Subcutaneous xenograft animal studies were performed to further investigate the tumorigenicity of BOLA2 in vivo. Compared to the WT group, the knockout of BOLA2 in HCC cells induced strong tumor growth suppression (Figure $6 \mathrm{D})$. The average tumor weights in the KO-1, KO-3, and WT groups were $0.61 \pm 0.08 \mathrm{~g}, 0.43 \pm 0.08 \mathrm{~g}$, and $0.98 \pm 0.06 \mathrm{~g}$, respectively (Figure $6 \mathrm{E}$ ). We found that xenografts derived from Hep3B-KO-BOLA2 cells exhibited decreased TH (Figure 6F, left panel). Intracellular iron is essential for HCC cell growth [23]. Another intriguing finding was that after the injection of Hep3B-KO-BOLA2 cells, the iron scores decreased markedly in the transplanted tumors of nude mice according to the histological examination of Prussian blue staining $(0.61 \pm 0.04$ vs. $0.99 \pm 0.10$ vs. $2.29 \pm 0.36$, Figure $3 \mathrm{~F}$, right panel). This observation led us to further explore the mechanism by which BOLA2 regulates the growth of $\mathrm{HCC}$ (Figure $6 \mathrm{~F}$, right panel).
A

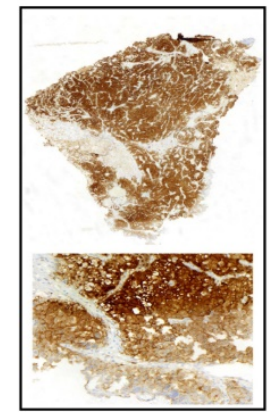

BOLA2

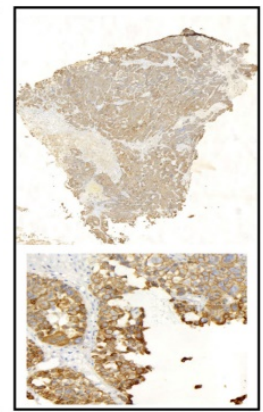

p62

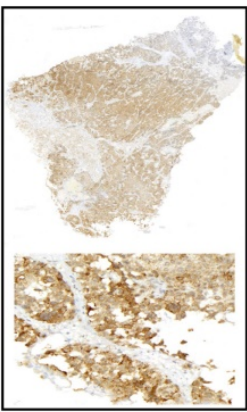

Keap1

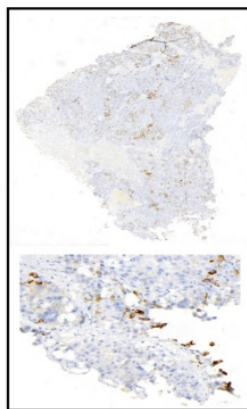

NFR2

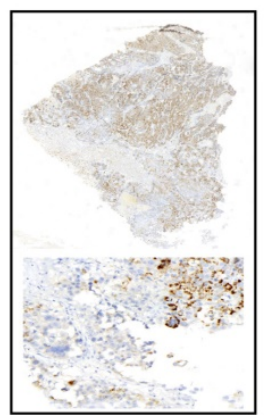

ATG4B

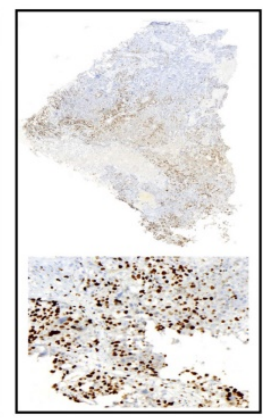

Ki-67

B

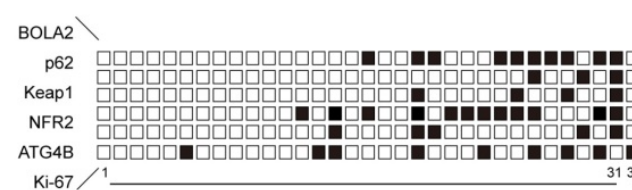

TH Negative

TH Positive
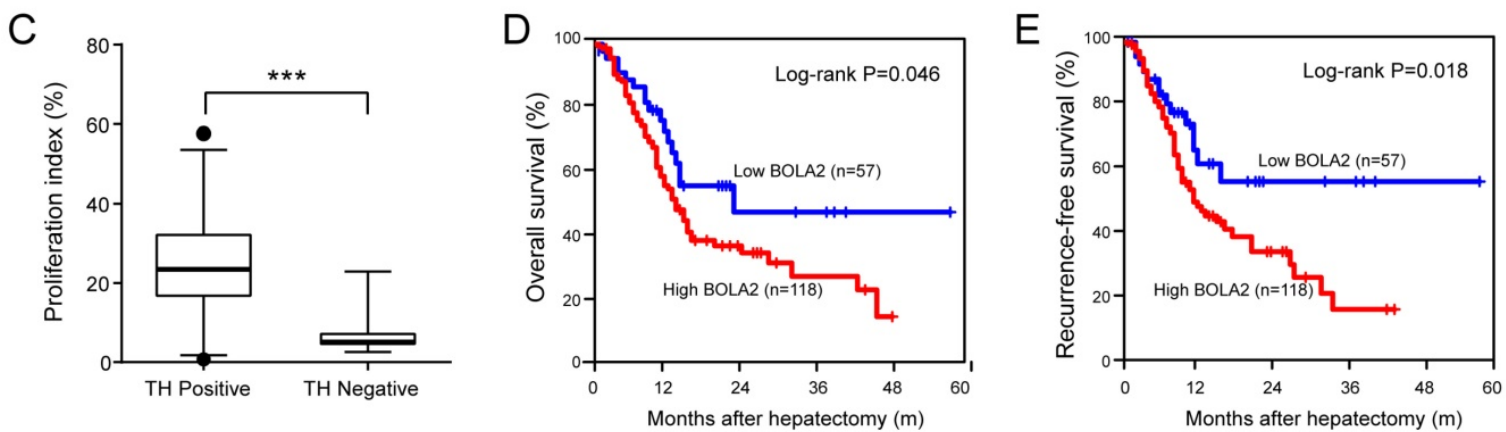

Fig. 4. (A) A summary of the immunohistochemical staining results of the training cohort. Membrane and cytoplasmic expression of BOLA2, p62, and Keap1 and the nuclear expression of NRF2 and Ki-67 were observed. (B) The samples are sorted from left to right in ascending order based on the presence of TH. The positive samples are indicated by black boxes. HCC patients with TH and lower BOLA2 expression had higher levels of NRF2, whereas patients with higher BOLA2 expression had increased ATG4B, p62 and Keapl levels. (C) Quantification of Ki-67 in HCC tissues with or without TN. Ki-67-positive cells are numbered, and box plots show the median, 25th and 75th percentiles, and minimum and maximum values. (D and E) Kaplan-Meier curves depicting overall survival (OS) and recurrence-free survival (RFS) according to the expression levels of BOLA2 in the validation cohort $(n=175)$.

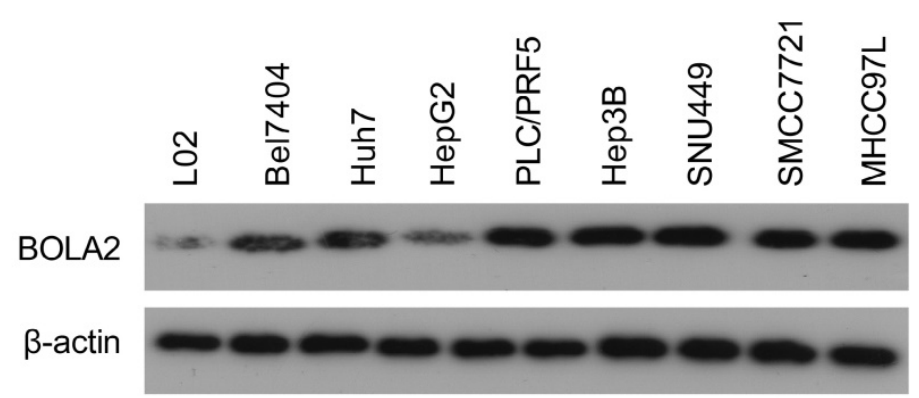

Fig. 5. Western blot analysis was used to examine the expression of BOLA2 in HCC cell lines versus immortalized human hepatocytes (L02). 
Table 3. Univariate and multivariate analyses of RFS and OS prognostic factors in HCC patients $(n=175)$.

\begin{tabular}{|c|c|c|c|c|}
\hline & RFS & & OS & \\
\hline Clinicopathologic variable & HR $(95 \% \mathrm{CI})$ & $P$ & HR $(95 \%$ CI) & $P$ \\
\hline \multicolumn{5}{|l|}{ Univariate analysis $\dagger$} \\
\hline Gender (male vs. female) & $1.061(0.867-1.584)$ & 0.215 & $1.106(0.923-1.316)$ & 0.135 \\
\hline Age, years (> 60 vs. $\leq 60)$ & $1.215(0.986-1.764)$ & 0.085 & $1.161(0.952-1.417)$ & 0.141 \\
\hline HBsAg (positive vs. negative) & $1.298(0.981-1.992)$ & 0.064 & $1.135(0.869-1.538)$ & 0.061 \\
\hline Albumin, g/L ( $\leq 35$ vs. $>35)$ & $1.052(0.897-1.963)$ & 0.089 & $1.195(0.995-1.436)$ & 0.056 \\
\hline Child-Pugh classification (B vs. A) & $1.231(1.053-1.768)$ & 0.037 & $1.292(1.084-1.852)$ & 0.043 \\
\hline Liver cirrhosis (presence vs. absence) & $1.312(1.097-1.635)$ & 0.016 & $1.369(1.106-3.145)$ & 0.013 \\
\hline Serum AFP level, ng/mL (> 20 vs. $\leq 20)$ & $1.452(1.079-1.894)$ & 0.036 & $1.209(1.012-2.174)$ & 0.046 \\
\hline Tumor diameter, $\mathrm{cm}(>5$ vs. $\leq 5)$ & $1.554(1.116-3.425)$ & 0.012 & $1.405(1.106-2.642)$ & 0.021 \\
\hline Tumor number (multiple vs. single) & $1.659(1.107-2.827)$ & 0.008 & $1.554(1.106-2.993)$ & 0.014 \\
\hline Tumor encapsulation (none vs. complete) & $1.152(0.932-1.436)$ & 0.072 & $1.304(1.046-2.214)$ & 0.025 \\
\hline Vascular invasion (presence vs. absence) & $2.113(1.462-4.834)$ & $<0.0001$ & $2.056(1.279-6.164)$ & $<0.0001$ \\
\hline Tumor differentiation (III/IV vs. I/II) & $1.478(1.187-1.769)$ & 0.022 & $1.352(0.994-1.967)$ & 0.069 \\
\hline Satellite nodules (presence vs. absence) & $1.841(1.267-3.156)$ & 0.004 & $1.731(1.036-1.948)$ & 0.010 \\
\hline TH (presence vs. absence) & $1.947(1.296-6.324)$ & 0.003 & $1.874(1.236-3.524)$ & 0.007 \\
\hline TNM stage (II/III vs. I) & $1.212(1.067-1.836)$ & 0.040 & $1.546(1.142-2.284)$ & 0.018 \\
\hline BOLA2 expression level (high vs. low) & $2.024(1.186-3.895)$ & 0.002 & $1.942(1.246-4.537)$ & 0.005 \\
\hline \multicolumn{5}{|l|}{ Multivariate analysis $\uparrow$} \\
\hline Gender (male vs. female) & NA & & NA & \\
\hline Age, years (> 60 vs. $\leq 60)$ & NA & & NA & \\
\hline HBsAg (positive vs. negative) & NA & & NA & \\
\hline Albumin, g/L ( $\leq 35$ vs. >35) & NA & & NA & \\
\hline Child-Pugh classification (B vs. A) & $1.078(0.967-1.842)$ & NS & $1.208(0.997-1.463)$ & NS \\
\hline Liver cirrhosis (presence vs. absence) & $1.102(0.954-1.863)$ & NS & $1.398(0.981-1.992)$ & NS \\
\hline Serum AFP level, ng/mL (> 20 vs. $\leq 20$ ) & $1.135(0.869-1.538)$ & NS & $1.364(0.967-1.842)$ & NS \\
\hline Tumor diameter, $\mathrm{cm}(>5$ vs. $\leq 5)$ & $1.195(0.995-1.436)$ & NS & $1.154(0.859-1.729)$ & NS \\
\hline Tumor number (multiple vs. single) & $1.874(1.236-3.524)$ & 0.007 & $1.768(1.023-3.969)$ & 0.019 \\
\hline Tumor encapsulation (none vs. complete) & NA & & $1.075(0.951-1.375)$ & NS \\
\hline Venous invasion (presence vs. absence) & $2.152(1.336-5.231)$ & $<0.0001$ & $1.994(1.253-4.564)$ & 0.002 \\
\hline Tumor differentiation (III/IV vs. I/II) & $1.208(0.946-1.764)$ & NS & NA & \\
\hline Satellite nodules (presence vs. absence) & $1.679(1.214-3.216)$ & 0.021 & $1.616(1.207-3.542)$ & 0.024 \\
\hline TH (presence vs. absence) & $2.342(1.678-7.429)$ & $<0.0001$ & $1.856(1.246-5.682)$ & 0.005 \\
\hline TNM stage (II/III vs. I) & $1.229(1.016-1.488)$ & 0.035 & $1.231(1.084-1.796)$ & 0.041 \\
\hline BOLA2 expression level (high vs. low) & $2.108(1.541-6.067)$ & 0.004 & $2.253(1.341-6.568)$ & $<0.001$ \\
\hline
\end{tabular}

\section{Involvement of p62-Keap 1 signalling in BOLA2-mediated HCC cell proliferation}

IHC staining was performed on serial sections of Hep3B cell transplantation tumors, and the protein expression of BOLA2 and p62 was significantly lower in the Hep3B-KO-BOLA2 group than in the WT group (Figure 7A). Proliferating cells were quantified by counting the number of Ki-67-positive cells; more Ki-67-positive cells were observed in WT tumors than in Hep3B-KO-BOLA2 tumors (Figure 7B). STRING was used to reveal the interactions of the BOLA2 pathway in HCC (Figure 7C), and a subnetwork of 20 genes was presented that included mTOR, AKT1, and MAPKP1, which are implicated in regulating tumor growth [24, 25]. High levels of p62 expression are needed for the activation of NRF2 or mTORC1, the induction of c-Myc, and the protection of HCC-initiating cells from oxidative stress-induced cell death [26]. Thus, we speculate that BOLA2 might promote the development of HCC and maintain cancer cell growth under metabolic stress conditions.

\section{Discussion}

HCC is highly lethal because of its aggressive metastasis and the minimally effective strategies available against metastasis [27]. HCC is characterized by its fast growth and multiple factors, including genetic and epigenetic alterations that cause uncontrolled cellular proliferation and metastasis. In the current study, BOLA2 overexpression was positively correlated with venous invasion, $\mathrm{TH}$, satellite nodules, and TNM stage. Moreover, the survival analysis showed that HCC patients with BOLA2 $2^{\text {high }}$ expression had shorter OS than those with BOLA2 ${ }^{\text {low }}$ expression. We hypothesized that BOLA2 might act as a tumor promoter to enhance HCC development. To confirm this hypothesis, functional studies showed that the knockout of BOLA2 reduced HCC cell proliferation in vitro and decreased tumor growth subsequent to $\mathrm{TH}$ in vivo. Similar to other investigations that reported the rapid growth rate in HCC, BOLA2 overexpression enhanced proliferation and colony formation in HCC cells, highlighting its importance in HCC progression. 
We previously demonstrated that $\mathrm{TH}$ was involved in fast-growth HCC. The precise mechanism underlying this BOLA2-mediated $\mathrm{TH}$ of tumor growth remains to be determined. BOLA2 expression is regulated by at least four mechanisms: (i) specific in-frame fusion transcript regulation, which controls the copy number; (ii) monothiol CGFS glutaredoxin binding partners [28]; (iii) a glutaredoxin-3 (GRX3)-dependent anamorsin maturation pathway [29]; and (iv) as a c-Myc-targeted gene in HCC [10]. In this work, we performed a TIMER analysis, and the results indicated that BOLA2 is highly associated with p62 expression in the tumor immunological microenvironment. A recent study showed that activation of the p62-Keap1-NRF2 pathway protects against ferroptosis in HCC cells [30]. The Keap1-Nrf2 system and autophagy are both involved in the oxidative stress response, metabolic pathways, and innate immunity, and the dysregulation of these processes is associated with pathogenic processes [31]. Therefore, we speculate that BOLA2 contributes to uncontrolled cellular proliferation, which may cause HCC development.

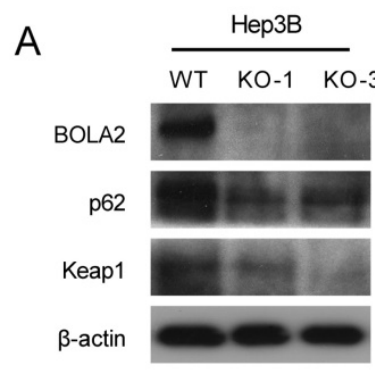

$\mathrm{B}$

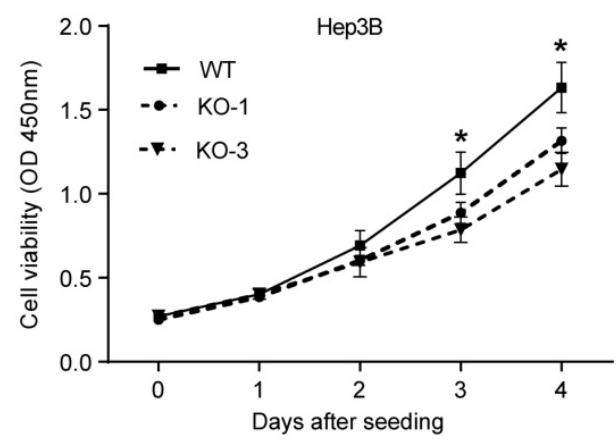

C

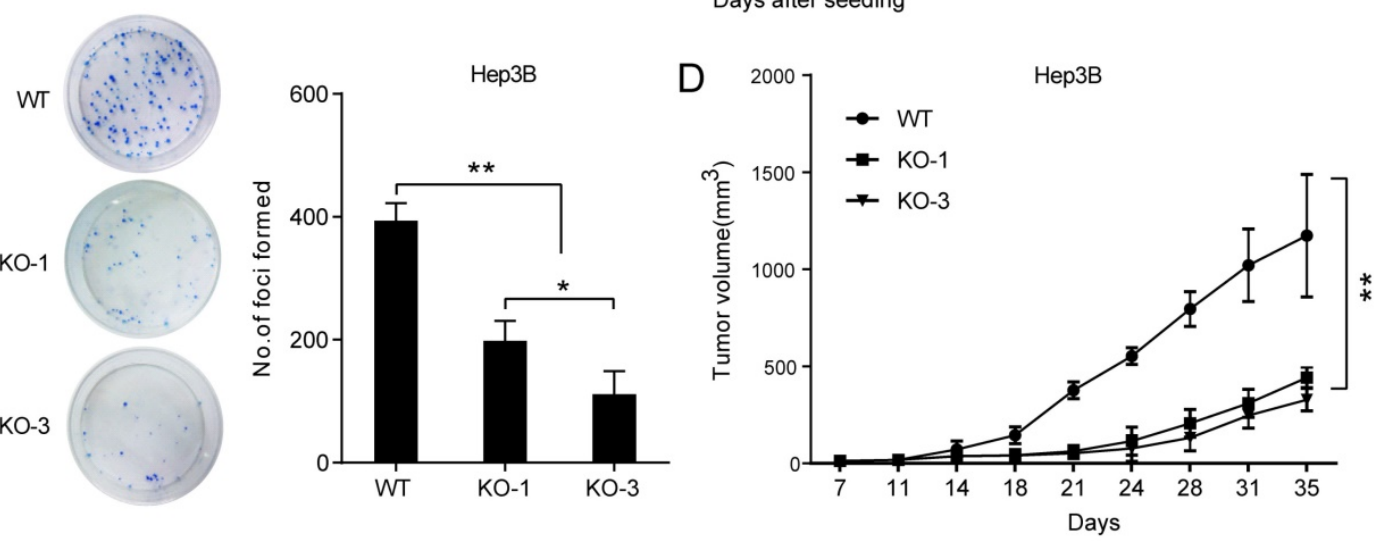

E
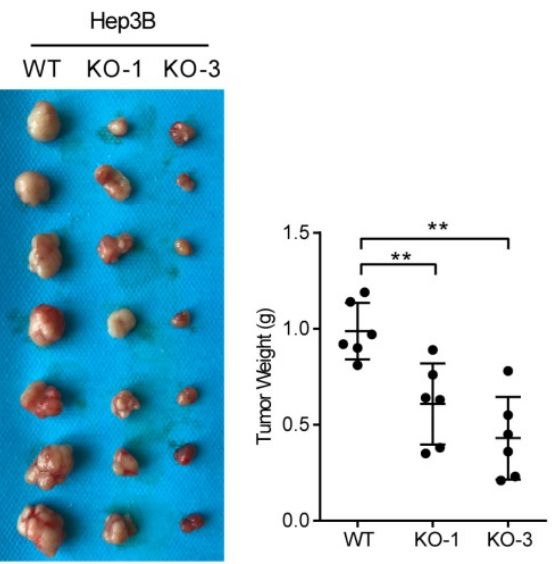

$\mathrm{F}$
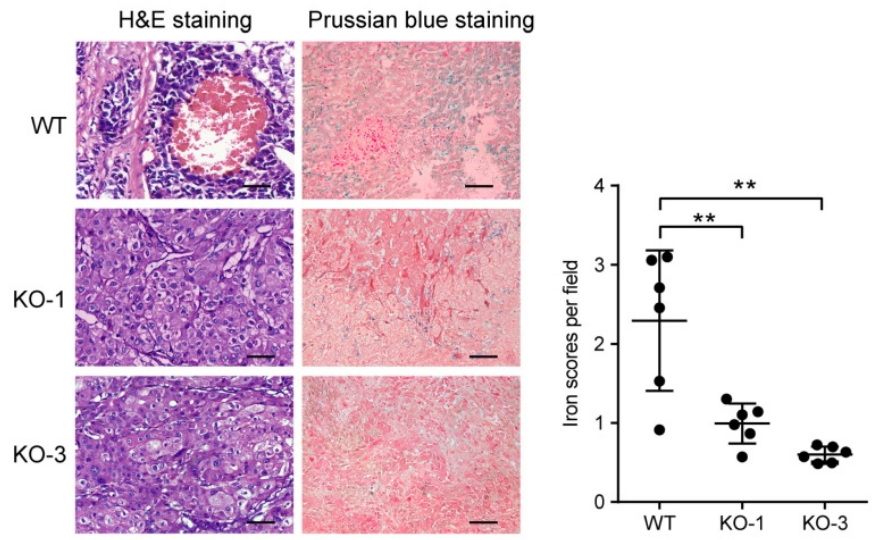

Fig. 6. BOLA2 knockout reduces the tumorigenicity of $\mathrm{HCC}$ cells in vitro and in a xenograft model. (A) BOLA2 knockout by CRISPR/Cas9 technology in Hep3B cells was confirmed by Western blot analysis. The activities of p62 and Keapl were reduced in BOLA2-deficient Hep3B cells. (B) BOLA2 knockout slows cell proliferation. (C) Colony formation assays were performed in the three BOLA2-deficient colonies derived from Hep3B and WT cells. The values are expressed as the mean \pm SD of three independent experiments. (D) Tumor growth curves in the three groups are shown on the indicated days after Hep3B cell (WT, KO-1, and KO-3) injection. The xenograft tumor volumes of each group were measured two times a week. (E) Representative images of subcutaneous tumors in nude mice injected with the indicated cells. Final tumor weights are summarized in a dot chart. The average tumor weight is expressed as the mean \pm SD of 6 mice. $(F)$ H\&E staining demonstrated that the KO of BOLA2 inhibited the TH phenotype of HCC in vivo (left panel). Corresponding Prussian blue staining shows iron particles scattered in the central part of the tumor with TH. The iron scores of the xenograft tumors were calculated and are depicted in the bar chart (right panel). 
A

WT
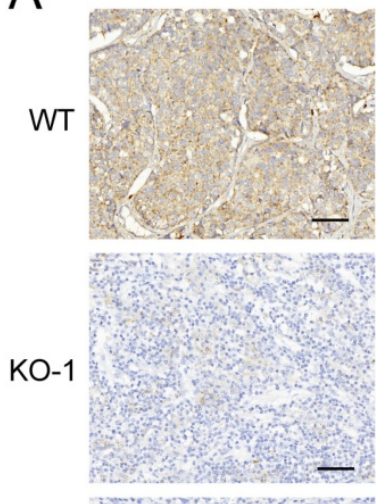

$\mathrm{KO}-3$

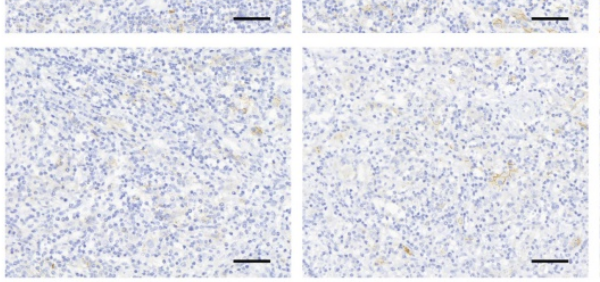

p62

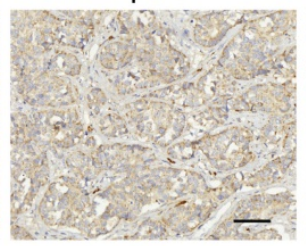

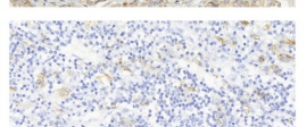
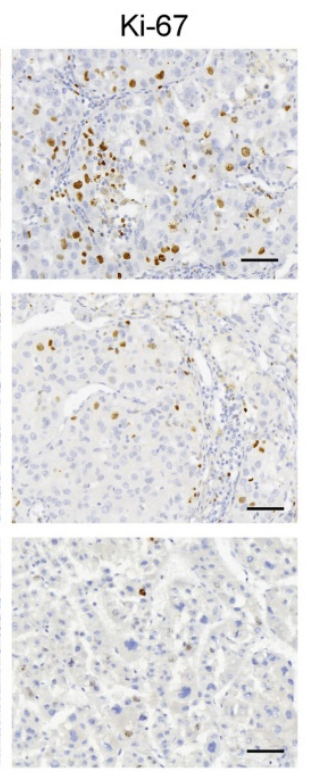

B

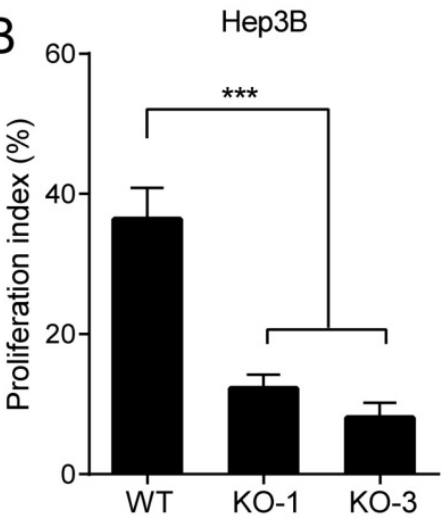

C
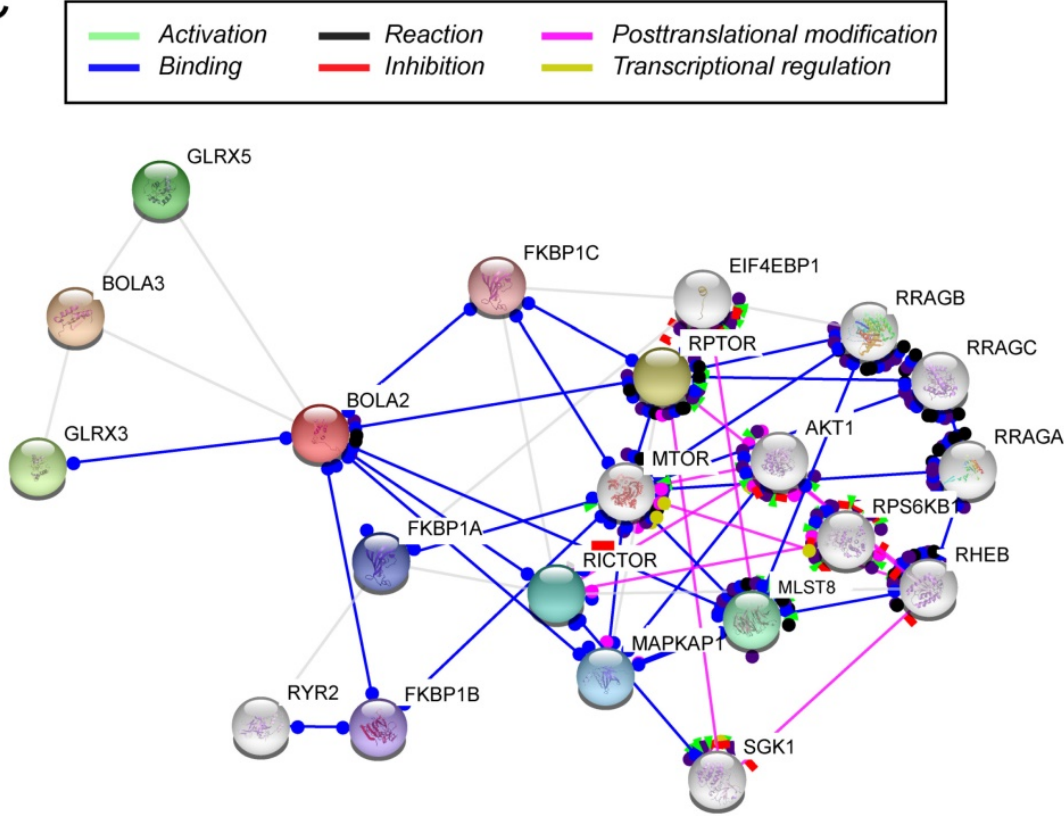

Fig. 7. (A) Representative immunohistochemistry staining of BOLA2, p62 and Ki-67 in transplanted tumor sections from Hep3B cells (WT, KO-1, and KO-3) injected into nude mice ( $\times 400$ magnification). Scale bar: $100 \mu \mathrm{m}$. (B) Comparison of Ki-67 staining in the transplanted tumors. (C) STRING database analysis of the PPI network for BOLA2. Interactions between 20 hub genes are illustrated with the cut-off criterion of a combined score $=0.7$. Network nodes represent proteins and edges represent protein-protein associations.

It is widely accepted that carcinogenesis is a multistep process that involves cell proliferation, adhesion, growth, and metabolism [32]. Increasing evidence has revealed alterations in iron metabolism in HCC that facilitate cancer cell growth [33]. Recent evidence suggests that the iron-mediated production of reactive oxygen species promoted autophagy in cancer stem cells [34]. TH is a very complex process in the tumor microenvironment and involves hypoxia, cell death, necrosis, the immune response, angiogenesis and nutrient-generating autophagy, etc.
[3]. We found the overexpression of BOLA2 in human $\mathrm{HCC}$ tumors with $\mathrm{TH}$; these findings reveal BOLA2 as a potential target against HCC.

Iron is essential for the proliferation of normal and neoplastic cells. Many cancers exhibit an increased requirement for iron, because the need for iron as a regulator is essential for growth and proliferation [9]. Excess liver iron (iron overload) is one of the major risks leading to increased $\mathrm{HCV}$ hepatitis, fibrosis, cirrhosis, and HCC [35]. Recent studies have reignited interest in the deregulation of 
iron homeostasis as an anticancer therapy [36, 37]. Further studies of BOLA2 in HCCs will be of interest to clarify its precise role in tumor growth and $\mathrm{TH}$.

\section{Conclusions}

Collectively, the present results indicate that BOLA2 is highly expressed in tumor tissues and is significantly correlated with a poor prognosis in HCC patients. Moreover, BOLA2 serves as a key emerging molecule in HCC cell growth and TH. These findings have important implications for identifying new therapeutic targets in HCC.

\section{Abbreviations}

HCC: hepatocellular carcinoma; BOLA2: BolA family member 2; TH: tumor hemorrhage; qRT-PCR: quantitative real-time polymerase chain reaction; IHC: immunohistochemistry; GEPIA: Gene Expression Profiling Interactive Analysis; TIMER: Tumor Immune Estimation Resource; OS: overall survival; RFS: recurrence-free survival.

\section{Acknowledgements}

We thank the TCGA for their efforts and for providing data. This study was supported by grants from the National Nature Science Foundation of China (No. 81372630, 81372631) and a project from the Nature Science Foundation of Hunan Province (No. 12JJ3118).

\section{Availability of data and materials}

The BOLA2 mRNA in HCC and normal tissues was obtained from the Oncomine database (www.oncomine.com). The correlation between BOLA2 expression and the overall survival of HCC patients was assessed by the Gene Expression Profiling Interactive Analysis (GEPIA) online tool.

\section{Ethics approval and consent to participate}

All procedures in this research have been approved by the XiangYa Hospital Central South University ethics committee and complied with the ethical guidelines (Permit Number: 201103768).

\section{Competing Interests}

The authors have declared that no competing interest exists.

\section{References}

1. Miller K, Siegel R, Lin C, Mariotto A, Kramer J, Rowland J, Stein K, Alteri R, Jemal A: Cancer treatment and survivorship statistics, 2016. CA Cancer J Clin 2016, 66(4):271-289.

2. Hernandez-Gea V, Toffanin S, Friedman SL, Llovet JM: Role of the microenvironment in the pathogenesis and treatment of hepatocellular carcinoma. Gastroenterology 2013, 144(3):512-527.

3. Yin T, He S, Liu X, Jiang W, Ye T, Lin Z, Sang Y, Su C, Wan Y, Shen G et al: Extravascular red blood cells and hemoglobin promote tumor growth and therapeutic resistance as endogenous danger signals. I Immunol 2015, 194(1):429-437

4. Hu K, Wang ZM, Li JN, Zhang S, Xiao ZF, Tao YM: CLEC1B Expression and PD-L1 Expression Predict Clinical Outcome in Hepatocellular Carcinoma with Tumor Hemorrhage. Transl Oncol 2018, 11(2):552-558.

5. Zhou Y-B, Cao J-B, Wan B-B, Wang X-R, Ding G-H, Zhu H, Yang H-M, Wang K-S, Zhang $X$, Han Z-G: hBolA, novel non-classical secreted proteins, belonging to different BolA family with functional divergence. Molecular and cellular biochemistry 2008, 317(1-2):61-68.

6. Nuttle X, Giannuzzi G, Duyzend M, Schraiber J, Narvaiza I, Sudmant P, Penn $\mathrm{O}$, Chiatante G, Malig M, Huddleston J et al: Emergence of a Homo sapiens-specific gene family and chromosome 16p11.2 CNV susceptibility. Nature 2016, 536(7615):205-209.

7. Frey A, Palenchar D, Wildemann J, Philpott C: A Glutaredoxin BolA Complex Serves as an Iron-Sulfur Cluster Chaperone for the Cytosolic Cluster Assembly Machinery. J Biol Chem 2016, 291(43):22344-22356.

8. Kowdley KV: Iron, hemochromatosis, and hepatocellular carcinoma. Gastroenterology 2004, 127(5):S79-S86.

9. Bogdan A, Miyazawa M, Hashimoto K, Tsuji Y: Regulators of Iron Homeostasis: New Players in Metabolism, Cell Death, and Disease. Trends Biochem Sci 2016, 41(3):274-286.

10. Hunecke D, Spanel R, Langer F, Nam SW, Borlak J: MYC-regulated genes involved in liver cell dysplasia identified in a transgenic model of liver cancer. J Pathol 2012, 228(4):520-533.

11. Tao YM, Liu Z, Liu HL: Dickkopf-1 (DKK1) promotes invasion and metastasis of hepatocellular carcinoma. Dig Liver Dis 2013, 45(3):251-257.

12. Altman DG, McShane LM, Sauerbrei W, Taube SE: Reporting Recommendations for Tumor Marker Prognostic Studies (REMARK): explanation and elaboration. PLoS Med 2012, 9(5):e1001216.

13. Ding S, Li Y, Shao X, Zhou H, Zeng R, Tang Z, Xia Q: Proteome analysis of hepatocellular carcinoma cell strains, MHCC97-H and MHCC97-L, with different metastasis potentials. Proteomics 2004, 4(4):982-994.

14. Zhou P, Wu L, Wu K, Jiang W, Li J, Zhou L, Li X, Chang S, Huang Y, Tan H et al: Overexpression of MMSET is correlation with poor prognosis in hepatocellular carcinoma. Pathol Oncol Res 2013, 19(2):303-309.

15. Jiang W, Wang Z, Li X, Li J, Huang Y, Fan X, Duan Y: Reduced high-mobility group box 1 expression induced by RNA interference inhibits the bioactivity of hepatocellular carcinoma cell line HCCLM3. Dig Dis Sci 2012, 57(1):92-98.

16. Hirsh M, Konijn AM, Iancu TC: Acquisition, storage and release of iron by cultured human hepatoma cells. J Hepatol 2002, 36(1):30-38.

17. Sanjana NE, Shalem $\mathrm{O}$, Zhang F: Improved vectors and genome-wide libraries for CRISPR screening. Nat Methods 2014, 11(8):783-784.

18. Tao YM, Huang JL, Zeng S, Zhang S, Fan XG, Wang ZM, Yang HX, Yuan XH, Wang $\mathrm{P}, \mathrm{Wu} \mathrm{F}$ : $\mathrm{BTB} / \mathrm{POZ}$ domain-containing protein 7: Epithelial-mesenchymal transition promoter and prognostic biomarker of hepatocellular carcinoma. Hepatology 2013, 57(6):2326-2337.

19. Tang Z, Li C, Kang B, Gao G, Zhang Z: GEPIA: a web server for cancer and normal gene expression profiling and interactive analyses. Nucleic Acids Res 2017, 45(W1):W98-W102.

20. Ponten F, Jirstrom K, Uhlen M: The Human Protein Atlas--a tool for pathology. J Pathol 2008, 216(4):387-393.

21. Li T, Fan J, Wang B, Traugh N, Chen O, Liu JS, Li B, Liu XS: TIMER: A Web Server for Comprehensive Analysis of Tumor-Infiltrating Immune Cells. Cancer Res 2017, 77(21):e108-e110.

22. Critelli R, Milosa F, Faillaci F, Condello R, Turola E, Marzi L, Lei B, Dituri F, Andreani S, Sighinolfi P et al: Microenvironment inflammatory infiltrate drives growth speed and outcome of hepatocellular carcinoma: a prospective clinical study. Cell Death Dis 2017, 8(8):e3017.

23. Ba Q, Hao M, Huang H, Hou J, Ge S, Zhang Z, Yin J, Chu R, Jiang H, Wang F et al: Iron deprivation suppresses hepatocellular carcinoma growth in experimental studies. Clin Cancer Res 2011, 17(24):7625-7633.

24. Chen $X$, Wang $Y$, Tao J, Shi $Y$, Gai X, Huang F, Ma O, Zhou Z, Chen H, Zhang $\mathrm{H}$ et al: mTORC1 Up-Regulates GP73 to Promote Proliferation and Migration of Hepatocellular Carcinoma Cells and Growth of Xenograft Tumors in Mice. Gastroenterology 2015, 149(3):741-752 e714.

25. Wang Y, Lin K, Chen S, Gu D, Chen C, Tu P, Jou Y: Overexpressed-eIF3I interacted and activated oncogenic Akt1 is a theranostic target in human hepatocellular carcinoma. Hepatology 2013, 58(1):239-250.

26. Umemura A, He F, Taniguchi K, Nakagawa H, Yamachika S, Font-Burgada J, Zhong Z, Subramaniam S, Raghunandan S, Duran A et al: p62, Upregulated during Preneoplasia, Induces Hepatocellular Carcinogenesis by Maintaining Survival of Stressed HCC-Initiating Cells. Cancer cell 2016, 29(6):935-948.

27. Wu D, Yang X, Peng H, Guo D, Zhao W, Zhao C, Zhou X: OCIAD2 suppressed tumor growth and invasion via AKT pathway in Hepatocelluar carcinoma. Carcinogenesis 2017, 38(9):910-919.

28. $\mathrm{Li} \mathrm{H}$, Outten $\mathrm{CE}$ : Monothiol CGFS glutaredoxins and BolA-like proteins: [2Fe-2S] binding partners in iron homeostasis. Biochemistry 2012, 51(22):4377-4389.

29. Banci L, Camponeschi F, Ciofi-Baffoni S, Muzzioli R: Elucidating the Molecular Function of Human BOLA2 in GRX3-Dependent Anamorsin Maturation Pathway. J Am Chem Soc 2015, 137(51):16133-16143.

30. Sun X, Ou Z, Chen R, Niu X, Chen D, Kang R, Tang D: Activation of the p62-Keap1-NRF2 pathway protects against ferroptosis in hepatocellular carcinoma cells. Hepatology 2016, 63(1):173-184 
31. Ichimura Y, Waguri S, Sou Y, Kageyama S, Hasegawa J, Ishimura R, Saito T, Yang Y, Kouno T, Fukutomi T et al: Phosphorylation of p62 activates the Keap1-Nrf2 pathway during selective autophagy. Mol Cell 2013, 51(5):618-631.

32. Gu Z, Wang H, Xia J, Yang Y, Jin Z, Xu H, Shi J, De Domenico I, Tricot G, Zhan F: Decreased ferroportin promotes myeloma cell growth and osteoclast differentiation. Cancer Res 2015, 75(11):2211-2221.

33. Kowdley KV: Iron, hemochromatosis, and hepatocellular carcinoma. Gastroenterology 2004, 127(5 Suppl 1):S79-86.

34. Pinnix ZK, Miller LD, Wang W, D'Agostino R, Jr., Kute T, Willingham MC, Hatcher H, Tesfay L, Sui G, Di X et al: Ferroportin and iron regulation in breast cancer progression and prognosis. Sci Transl Med 2010, 2(43):43ra56.

35. Willis G, Wimperis JZ, Lonsdale R, Jennings BA: Haemochromatosis gene mutation in hepatocellular cancer. Lancet 1997, 350(9077):565-566.

36. Torti SV, Torti FM: Iron and cancer: more ore to be mined. Nature Reviews Cancer 2013, 13(5):342-355.

37. Crielaard BJ, Lammers T, Rivella S: Targeting iron metabolism in drug discovery and delivery. Nat Rev Drug Discov 2017, 16(6):400-423. 